\title{
Rationale of Therapy in the Patient with Acute Myocardial Infarction and Life-Threatening Arrhythmias: A Focus on Bretylium
}

\author{
BENEDICT R. LUCCHESI, PhD, MD
}

Experimental evidence suggests a number of pathologic and electrophysiologic mechanisms that may help initiate ventricular arrhythmlas accompanylng myocardial ischemla and infarction. Early and late phase events are associated with reentry or an enhancement of focal mechanisms, or both. These can initiate ventricular tachycardia (VT) or ventricular fibrillation (VF), or both. The presence of distinct mechanisms that may initiate and maintain IIfe-threatening dysrhythmias early in myocardial Ischemia suggest different pharmacologic approaches for their prevention or suppression. Another consideration concerns patients subjected to coronary artery angioplasty or thrombolytic therapy and the development of arrhythmlas associated with reperfusion of the once ischemic myocardium. The electrophysiologic mechanisms associated with reperfusion arrhythmias are unknown, and little is known about approprlate therapy for each episode of cardlac dysrhythmia.

Ventricular extrasystoles or VT usually precedes VF. These premonitory arrhythmias are poor criteria for the institution of antiarrhythmic drug therapy, because VF develops within 1 to 10 minutes after the appearance of the rhythmic disturbances. Some authorities suggest that all patients with acute myocardial infarction should recelve prophylactic antlarrhythmic therapy, because warning arrhythmlas either do not occur at all or provide insufficient time to intervene pharmacologically.
Many of the new class I antiarrhythmic agents effectively reduce the frequency of premature ventricular depolarizations, but lack specific antifibrillatory activlty. However, the recent introduction of bretylium into clinical cardiology opens a new approach to preventing life-threatening ventricular dysrhythmias. Along with other members of class III, bretylium exerts different cardiac electrophysiologic effects than do the other 3 classes of drugs. Bretylium has been designated as class III because It increases the action potential duration and prolongs the effective refractory period. The other class III drugs, including amiodarone, sotalol, clofilium and pranolium, experimentally prevent the establishment of a reentry pathway that can initiate VF. Bretyllum along with these other class III agents is primarily antifibrillatory rather than antiarrhythmic. Thus, antiarrhythmic agents that reduce the frequency and complexity of premature ventricular depolarizations are not necessarily antifibrillatory. It is necessary to reorient our thinking about how pharmacologic interventions may influence the course of events in patients at risk of developing life-threatening ventricular arrhythmias. Because the lethal event is most often associated with VF, it may be sufficlent to have an agent that protects against this electrophysiologic disorder even though it does not completely prevent or suppress other ventricular arrhythmias.

(Am J Cardiol 1984;54:14A-19A)
The most catastrophic event that can happen to a patient with acute myocardial infarction (MI) is the development of primary ventricular fibrillation (VF), which is often associated with previous electrocardiographic evidence of ventricular electrical instability as demonstrated by the occurrence of premature ventric-

From the Department of Pharmacology, The University of Michigan Medical School, Ann Arbor, Michigan.

Address for reprints: Benedict R. Lucchesi, PhD, MD, Department of Pharmacology, The University of Michigan Medical School, Ann Arbor, Michigan 48109. ular complexes or episodes of ventricular tachyarrhythmia, or both. ${ }^{1}$ Because this discussion will focus on patients with coronary artery disease, the term sudden coronary death becomes more appropriate than the broader concept of sudden cardiac death. Within this context, an effort will be made to provide a rational basis for the selection of drug therapy for the prevention of recurrent episodes of life-threatening ventricular tachycardia (VT) and VF. Effective therapeutic interventions would be most wanted for those individuals who are at high risk as determined by the presence of coronary artery disease and left ventricular character- 
istics associated with recurrent episodes of ventricular tachyarrhythmia.

\section{The Necessary Substrate for Ventricular Tachyarrhythmia and Ventricular Fibrillation}

Myocardial ischemia and MI commonly are accompanied by the development of ventricular arrhythmias or tachyarrhythmias, or both, because of alterations in the cellular electrophysiologic characteristics of those myocardial cells involved in the ischemic process. ${ }^{2}$ The underlying alterations in cellular electrophysiologic aspects can further be influenced by the activity of the autonomic nervous system. .,4 $^{3,4}$

Studies by Waldo and Kaiser ${ }^{5}$ and Boineau and Cox demonstrated that the period immediately after acute coronary artery occlusion was associated with transient or sustained periods of continuous electrical activity, or local fibrillation, within the ischemic or infarcted myocardium, or both. Persistence of continuous electrical activity beyond the $T$ wave of the preceding impulse almost always was associated with ventricular extrasystoles. Therefore, the presence of sustained electrical diastolic activity or localized fibrillation may provoke the development of VT or VF. The implication is that persistent diastolic activity within the area of ischemic myocardial injury spreads to the remainder of the ventricle, resulting in abnormal rhythm. The electrophysiologic properties of the ischemic myocardium, such as enhanced threshold of excitability, shortened refractory period, decreased conduction velocity and increased inhomogeneity of the recovery of excitability, provided a suitable substrate for initiation and perpetuation of VF. ${ }^{7-11}$ The localized areas of sustained excitation function as a source of reentrant activity ${ }^{12,13}$ and suggest that a potential site of action for an antiarrhythmic drug could be located within the ischemic region or the normal myocardium so as to result in electrophysiologic alterations that would decrease the disparity between the 2 regions or prevent the continuous excitation within the ischemic zone from entering the surrounding normal myocardium.

Recent data support the concept that early arrhythmias associated with coronary artery occlusion, and most likely the development of VF, are due to reentry mechanism, whereas late occurring arrhythmias are more likely the result of enhanced or abnormal automaticity. ${ }^{12-17}$

The electrophysiologic effects of lidocaine have been studied in the in situ canine heart in which epicardial electrograms were recorded from the normal and ischemic zones. ${ }^{18}$ Lidocaine delayed activation and prolonged the effective refractory period of the infarcted zone of the heart, without affecting these parameters in the normal myocardial region; the drug primarily decreased the disparity in the effective refractory periods of the 2 myocardial regions. Subsequent studies ${ }^{19}$ showed that lidocaine affects intraventricular conduction as do quinidine and procainamide. Therefore, lidocaine may abort reentrant ventricular arrhythmias by depressing the conduction velocity within the region of myocardial injury to the point of extinction of the reentrant wave-front. A similar mechanism has been proposed for verapamil, which prolongs conduction time in the ischemic myocardial region, but not in the normal zone. ${ }^{20}$

More recently, the technique of programmed electrical stimulation in the chronically ischemic canine heart has been used to assess the ability of disopyramide to prevent reentrant tachyarrhythmias. ${ }^{21}$ The drug was effective only at a plasma concentration which exceeded that usually considered to be therapeutic. These findings were not unlike those of Horowitz et a ${ }^{22}$ who used programmed electrical stimulation to induce reentrant rhythms in patients with recurrent episodes of VT and in whom the effective plasma concentrations of disopyramide were well beyond the upper limit of what is considered the therapeutic range.

The results of such studies might be interpreted as suggesting that currently available class I antiarrhythmic drugs might have the ability to suppress or prevent reentrant ventricular rhythms, but they will only do so at dosages that will not be tolerated by most patients. The latter point is illustrated by the results of Lie et $\mathrm{al}^{23}$ who studied 212 patients with acute MI randomized by 2 treatment groups. Among 107 patients receiving lidocaine (100-mg loading dose followed by 3 $\mathrm{mg} / \mathrm{min}$ for 48 hours), no episode of primary VF occurred. This result contrasted with 9 episodes of primary VF among 105 patients receiving placebo (5\% dextrose and water). Side effects occurred in $15 \%$ of the patients treated with lidocaine and were more common in older patients.

'The major electrophysiologic effects of the class I antiarrhythmic drugs in suppressing reentrant rhythms are due to their ability to convert unidirectional block into bidirectional block by slowing conduction in both normal and depressed myocardial regions. The class I drugs also prolong the effective refractory period. Therefore, it is theoretically possible that class I antiarrhythmic agents might have the potential to facilitate the induction of reentrant rhythms, depending on the balance of their effects on conduction velocity and refractoriness in normal and ischemic myocardium..$^{21,24}$ Class I antiarrhythmic drugs perhaps will be found to prevent recurrent episodes of VT and prevent VF only at plasma concentrations that are not tolerated by a significant number of patients. Failure of previous clinical trials to provide clear-cut evidence for a reduction in the frequency of primary VF despite a reduction in the frequency or complexity of premature ventricular complexes may be related to the finding that higher plasma concentrations of the class I drugs are required to prevent reentrant rhythms that lead to VF.

Electrophysiologic abnormalities can be demonstrated in many patients who have survived an episode of out-of-hospital cardiac arrest not associated with acute MI. ${ }^{25-28}$ The continued presence of an electrically unstable myocardial substrate is suggested by the finding that VT will develop in $81 \%$ of such patients in response to programmed electrical stimulation. The ability to induce VT by electrical stimulation is rarely, if ever, observed in patients who do not possess underlying heart disease, ${ }^{29}$ thus emphasizing the importance 
of a vulnerable substrate for the initiation and maintenance of lethal tachyarrhythmia.

The importance of the presence of a vulnerable myocardial substrate for the development of sudden coronary death has been emphasized by the observation of Schuster and Bulkley. ${ }^{30}$ They identified 2 groups with early postinfarction angina: those with ischemia at a distance and those with ischemia in the infarct zone. Patients with ischemia at a distance constitute a subset of hemodynamically stable patients who face an unexpectedly high mortality because of a persistently ischemic myocardium which provides the proper substrate for the genesis of reentrant rhythms and the development of VF.

\section{Evaluating the Antiarrhythmic vs the Antifibrillatory Action of Pharmacologic Interventions}

The presence of a vulnerable substrate needed for the genesis of life-threatening tachyarrhythmias is supported by the use of programmed electrical stimulation to elicit ventricular arrhythmias, as already discussed herein, and has led to the use of provocative testing procedures in the identification of pharmacologic agents for prophylactic management of patients determined to be at high risk of sudden coronary death. In most patients with recurrent sustained VT, the arrhythmia occurs sporadically; therefore, empiric selection of therapy is marked by fallibility in both the choice and the dose of antiarrhythmic agent. Electrophysiologic testing is believed to provide an objective basis on which rational pharmacologic therapy can be selected, ${ }^{31}$ because recurrent VT can be reproducibly initiated by programmed electrical stimulation in most patients with chronic ischemic heart disease.

The use of an electrophysiologic protocol for drug selection is based on several assumptions: (1) the tachycardia produced in the laboratory by programmed stimulation is identical to clinical tachyarrhythmia; (2) the response to drug therapy in the laboratory predicts the clinical response; and (3) the ability to prevent electrically induced VT by drug treatment predicts the inability of the heart to develop VF, especially if an ischemic episode superimposes on a vulnerable substrate. Is the prevention of electrically induced arrhythmias by drug therapy synonomous with the prevention of sudden coronary death? Probably not. Although the first and second assumptions may be established, the third is not, because an acute ischemic episode is not part of the testing procedure. The true efficacy of an intervention can only be determined by looking at its potential to prevent sudden coronary death. Programmed electrical stimulation and acute pharmacologic testing may not be valuable in helping to identify those at risk of sudden coronary death and in establishing treatment regimens. The identification of a truly effective agent will be determined by its ability to prevent VF, an end point seldom achieved during provocative testing procedures. It may also be true that a drug fails to prevent the initiation of tachyarrhythmia by programmed electrical stimulation may still successfully prevent a spontaneous recurrence. This would be especially true of those agents that accumulate in myocardial tissue over time and show little correlation between concentration of drug in the plasma and therapeutic efficacy.

Considering the magnitude of the problem of sudden coronary death, there is a need for an intensive program aimed at the development of new therapeutic interventions as the only practical approach to the reduction in mortality among those identified to be at risk. The ideal antiarrhythmic, or to be more precise, antifibrillatory agent, does not exist. Despite extensive clinical studies, it is not possible to demonstrate that $\geq 1$ of the newer pharmacologic agents possess any promise as being the ideal agent for the prevention of sudden coronary death. May et $\mathrm{a}^{32}$ recently reviewed the results of 14 clinical trials involving 3,625 patients with documented MI who were treated with 1 of 4 antiarrhythmic drugs including quinidine, disopyramide, procainamide and lidocaine. Despite the fact that each agent has been reported to suppress ventricular arrhythmias in the acute phase of MI, and lidocaine may reduce the incidence of in-hospital VF, not 1 of the trials has demonstrated that suppression of ventricular premature complexes is accompanied by a statistically significant reduction in overall mortality.

Ruskin et $\mathrm{al}^{33}$ employed electrophysiologic testing in 98 patients who had survived an episode of cardiac arrest. Six of the 98 patients had been taking antiarrhythmic drugs at the time of cardiac arrest. Before the administration of antiarrhythmic therapy, no patient had a documented episode of VT or symptoms suggestive of it. After therapy was initiated, however, cardiac arrest occurred with documented VF or VT within 3 to 5 months in the 6 patients. Electrophysiologic testing demonstrated that these patients were more susceptible to inducible VT while taking antiarrhythmic drugs than in the absence of drug therapy. When the drugs were withdrawn for $\mathbf{4 8}$ hours, no patient responded to electrophysiologic testing with the induction of ventricular tachyarrhythmias. The clinical implication of this study is significant and provides strong circumstantial evidence that antiarrhythmic drugs can contribute to episodes of cardiac arrest.

The recurrence rate of sudden death is extremly high (30 to $40 \%$ ), especially among those whose cardiac arrest was not associated with acute MI. Treatment with an antiarrhythmic agent would seem essential. In such patients, programmed electrical stimulation can often induce sustained VT or VF, or both. What is unclear, however, is whether a drug that prevents electrically induced arrhythmias in a patient rescued from cardiac arrest will also be effective in preventing spontaneous recurrence of sudden coronary death. Roy et $\mathrm{al}^{34}$ reported their long-term experience after electrophysiologic testing in 119 patients resuscitated from cardiac arrest. Repeat electrophysiologic testing was performed in 60 patients after initiating therapy and 41 were not inducible. The rate of recurrent sudden death in the 41 patients over a follow-up period of 17 months was $15 \%$. The long-term recurrence rate of sudden death in patients who remained inducible was $21 \%$ ( 4 of 19 ). There were 47 sudden death survivors in whom sustained arrhythmias could not be induced. Ten of $29(34 \%)$ treated patients had recurrent sudden death as did 5 of 18 who 
received no specific antiarrhythmic therapy. There were 9 patients who received amiodarone and in whom catheter-induced arrhythmias could not be prevented when reevaluated after acute administration. Only 1 of the 9 patients on amiodarone therapy experienced recurrent sudden death. These studies suggest that successful abolition of induced arrhythmias is a meaningful way of assessing drug efficacy and that amiodarone might be reserved for patients whose condition is refractory to standard antiarrhythmic agents.

Invasive electrophysiologic testing currently may be the best approach in selecting effective antiarrhythmic therapy in patients who have had a life-threatening ventricular arrhythmia. The appropriate means of determining therapy in patients who are at high risk of sudden death but who only demonstrate nonsustained VT and complex ventricular ectopic depolarizations remains uncertain. Spielman et $\mathrm{al}^{35}$ reported that electrophysiologic testing is more effective than empirical drug selection in high-risk patients who have not manifested recurrent VT or out-of-hospital cardiac arrest.

\section{Antiarrhythmic vs Antifibrillatory Drugs}

There has been an "explosive" appearance of new antiarrhythmic agents (Table I) that are reported to be effective in reducing the frequency of premature ventricular complexes, but most lack specificity with respect to antifibrillatory activity. Thus, current procedures used to identify an agent capable of preventing sudden cardiac death may be inadequate if the end point is something other than VF. The antiarrhythmic drugs currently available in the United States for the long-term management of patients with life-threatening arrhythmias are quinidine, procainamide, disopyramide, propranolol, timolol, metoprolol and phenytoin. None is considered entirely suitable for long-term prophylactic use in the prevention of sudden coronary death. Of the new class I agents including aprindine, tocainide, mexiletine, encainide, ethmosin, flecainide and pirmenol, none is known specifically to prevent VF in either the experimental animal or man. There are limited published preclinical data with respect to many of these agents, and already several are proving to have serious toxic effects.

Studies recently reviewed by Singh and Venkatesh ${ }^{36}$ demonstrate a clear rationale for the prophylactic use of $\beta$-adrenergic receptor blocking agents (propranolol and timolol) in subsets of patients with ischemic heart disease for the purpose of reducing the incidence of sudden death and the recurrence of MI. Although the beneficial result is attributed to the establishment of $\beta$-adrenergic receptor blockade, the exact mechanism of the salutary effect is not known. The antiischemic effects that accrue as a result of inhibiting adrenergic responses of cardiac $\beta$-receptors may serve to prevent the initiating triggering event from acting on a vulnerable myocardial substrate. Therefore, a primary antiarrhythmic or antifibrillatory action may not be present in many members of this class, despite their ability to reduce the incidence of lethal arrhythmic events in patients with ischemic heart disease. Despite their demonstrated efficacy in reducing morbidity in survi-
TABLE I Classification of Antiarrhythmic Drugs

\begin{tabular}{|c|c|}
\hline Class & Drugs \\
\hline I & $\begin{array}{l}\text { Quinidine, procainamide, disopyramide, penytoin, } \\
\text { lidocaine } \\
\text { Mexiletine, tocainide } \\
\text { Aprindine, encainide, lorcainide, flecainide, ethmozin, } \\
\text { propafenone, pirmenol }\end{array}$ \\
\hline $\begin{array}{l}\text { II } \\
\text { III } \\
\text { IV }\end{array}$ & $\begin{array}{l}\text { Propranolol, timolol, atenolol, metoprolol, nadolol } \\
\text { Bretylium, sotalol, amiodarone, clofilium, pranolium } \\
\text { Verapamil, diltiazem, bepridil }\end{array}$ \\
\hline
\end{tabular}

vors of acute MI, therapy with the $\beta$-adrenergic receptor blocking agents may not be applicable to all survivors with acute MI or to those patients rescued from sudden coronary death but in whom MI has not occurred. Despite dramatic progress, the need for alternative pharmacologic interventions for patients at risk of sudden coronary death is clearly recognized.

The recent introduction of bretylium into clinical cardiology has suggested a new approach to the prevention of life-threatening ventricular arrhythmias. The precise mechanism by which bretylium produces its antifibrillatory effect is unknown, but its cellular electrophysiologic effects differ significantly from those of the class I and class II antidysrhythmic drugs. Bretylium has been classified as belonging to a group of agents that are placed in class III because they have the property of increasing the ventricular action potential duration and prolonging the effective refractory period. Others considered to be class III antidysrhythmic agents include amiodarone, sotalol, clofilium and pranolium. ${ }^{37}$

\section{Indirect and Direct Cardiac Actions of Bretylium}

Alterations in adrenergic neuronal function: The acute single dose of bretylium leads to a biphasic cardiovascular response in both experimental animals and man. ${ }^{38-40}$ The initial displacement of norepinephrine from adrenergic nerve terminals results in an increase in arterial blood pressure, vascular resistance and heart rate and may augment the frequency of ventricular premature complexes. The initial response begins to dissipate by 20 to 30 minutes and blood pressure, vascular resistance and heart rate begin to decrease as peripheral sympathetic tone decreases secondary to the adrenergic neuronal blocking effects of bretylium (chemical sympathectomy). The latter effect predominates during the chronic phase of therapy and may be circumvented by the previous administration of a tricyclic antidepressant drug, e.g., protriptyline or doxepin, which effectively blocks the uptake mechanism in adrenergic neurons, thereby preventing bretylium from gaining access to the adrenergic nerves. Therefore, the catecholamine release and subsequent sympatholytic effects of bretylium can be prevented without affecting the electrophysiologic effects of the quaternary amine on the heart.40,41 The complicating effects of catecholamine release can be minimized or prevented by pretreatment with a tricyclic antidepressant ${ }^{40,41}$ or by the previous administration of a $\beta$-adrenergic receptor antagonist. ${ }^{42}$ 


\section{Direct Electrophysiologic Effects of Bretylium}

The direct electrophysiologic effects of bretylium resulting in prolongation of the ventricular refractory period can be demonstrated with long-term drug administration and in the absence of endogenous catecholamine release ${ }^{43}$ The direct electrophysiologic and antifibrillatory effects of bretylium were noted to parallel the myocardial rather than the serum concentrations of the drug, with the peak response occurring 3 to 6 hours after intravenous administration. Our data suggest that the kinetics of the electrophysiologic and antifibrillatory effects of bretylium parallel those of drug accumulation in myocardial tissue, whereas the kinetics of catecholamine release and serum concentration of the drug are dissimilar. These studies demonstrate the marked time and dose-dependent differences in response to bretylium. The delayed response in the increase in the ventricular refractory period and fibrillation threshold with small doses might be converted to a more immediate response by a larger initial dose which results in a more rapid accumulation of the drug in myocardial tissue. The limitation in the rate of administration of bretylium is due to the concomitant effects on the adrenergic neuronal stores of norepinephrine.

The electrophysiologic effects of intravenous bretylium on the conduction of premature impulses and excitation threshold in the normal and ischemic myocardium have been described. ${ }^{44,45}$ There was a significant delay in the conduction of impulses from normal myocardial tissue to the border of the ischemic heart muscle and a decrease in the disparity between excitation thresholds of adjoining ischemic and normal myocardial regions. As noted by others, ${ }^{42-44}$ the electrophysiologic effects of bretylium were delayed in their appearance, once again suggesting the need for the drug to accumulate in myocardial tissue. However, the effects of bretylium on the VF threshold and defibrillation threshold occur within minutes of administration.

The most prominent electrophysiologic actions of bretylium are an increase in the threshold current required to induce VF and a prolongation in the ventricular effective refractory period, ${ }^{46-50}$ an effect that is more prominent than that observed with other currently available antiarrhythmic drugs grouped under class I. ${ }^{4-50} \mathrm{~A}$ most interesting observation is the spontaneous conversion of VF to sinus rhythm after the administration of bretylium. ${ }^{51}$ Chemical defibrillation has not been observed with other antiarrhythmic agents and is a property possessed by bretylium and other investigational drugs grouped as class III antiarrhythmic agents. ${ }^{37,52}$ The ability of bretylium to exert an antifibrillatory effect is unlikely to be a result of its actions on the sympathetic nervous system, because guanethidine, a compound that exerts similar actions on the sympathetic nervous system, does not possess an antifibrillatory action when studied in the experimental animal. ${ }^{48,53}$ Bretylium is equally as effective in the heart of reserpine-treated animals ${ }^{53}$ and in the denervated heart ${ }^{54}$ as it is in the normal heart. Several currently available drugs (quinidine, lidocaine, phenytoin, disopyramide, procainamide and propranolol) are reported to increase the current required to achieve ventricular defibrillation in the experimental animal. ${ }^{55}$ However, bretylium decreases the electrical threshold for successful defibrillation..$^{56}$

Haynes et $a^{57}$ compared the immediate and shortterm effects of bretylium and lidocaine in the management of 146 victims of out-of-hospital VF in a randomized blinded trial. The administration of bretylium (500 mg intravenously) or lidocaine $(100 \mathrm{mg}$ intravenously) followed by resuscitative measures resulted in the development of an organized cardiac rhythm in most patients ( 89 and $93 \%$ in the bretylium and lidocaine groups, repsectively). The lidocainetreated group showed a slightly greater tendency towards conversion to asystole ( 46 vs $34 \%$ ), whereas bretylium-treated patients had a somewhat greater tendency towards recurrent VF ( 49 vs $39 \%$ ). Chemical defibrillation was not observed with either of the drug treatments. There was no difference with respect to the number of patients successfully defibrillated in each of the groups. Therefore, the investigators did not observe any significant differences between the 2 groups of patients in the response to defibrillation, in resuscitation or in mortality.

Nowak et al ${ }^{58}$ conducted a randomized double-blind study comparing bretylium with saline solution (in addition to Advanced Cardiac Life Support protocol drugs and procedures) as a first-line drug in patients with cardiopulmonary arrest. They concluded that the aggressive use of bretylium $(10 \mathrm{mg} / \mathrm{kg})$ as a first-line agent in the treatment of out-of-hospital VF significantly increases the chances for successful resuscitation. Furthermore, the administration of bretylium followed by lidocaine reduced the incidence of recurrent VF.

The observation that VF develops in $40 \%$ of patients with acute MI with significant warning arrhythmias suggests that an effective antiarrhythmic drug should be employed as a routine prophylactic measure. Clinical studies in the setting of acute MI provide convincing evidence that bretylium is effective in reducing the incidence of VF . ${ }^{59-63}$

\section{Prospects for the Future}

There has been substantial progress in recent years with respect to identifying subsets of patients who are at risk of sudden coronary death. Both surgical and electrical means of preventing sudden death in the most difficult-to-manage patient groups have been attempted with impressive results. However, a critical need remains for the development of more reliable and effective therapeutic agents capable of preventing VF. The results being reported with amiodarone, ${ }^{64,65}$ clofilium $^{66}$ and sotalol, 67,68 all members of class III, suggest that these agents have electrophysiologic effects that will prevent induction of a reentrant rhythm and development of a lethal arrhythmia when a triggering event is superimposed on the vulnerable substrate of an ischemic myocardium.

\section{References}

1. Blgger JT, Dresdale RJ, Helssenbuttel RH, Weld FW, WIt AL. Ventricular antythmias in ischemic heart disease: mechanism, prevalence, significance and management. Progr Cardiovasc Dis 1977;19:225-300. 
2. Wht AL, Blgger JT. Possible electrophysiological mechanisms for lethal armythmias accompanying myocardial ischemia and infarction. Circulation 1975;51, 52(suppl II):96--115.

3. Corr PB, Cillis RA. Autonomic neural influences on the dysrhythmias resulting from myocardial infarction. Circ Res 1978;43:1-9.

4. Levy M. Role of the autonomic nervous system in the pathogenesis of dysrhythmias in acute myrocardial infarction and sudden cardiac death. In: Sobel BE, Dingell JV, Mock MB, eds. Electrophysiological Mechanisms Underlying Sudden Cardiac Death. New York: Futura, 1982:85-92.

5. Waldo AL, Kaiser GA. A study of ventricular arrhythmias associated with acute myocardial infarction in the canine heart. Circulation 1973;47: 1222-1228.

6. Bolneau JP, Cox JL. Slow ventricular activation in acute myocardial infarctions: a source of reentrant premature ventricular contractions. Circulation 1973;48:702-7*13.

7. Han J, Moe CK. Non-uniform recovery of excitability of ventricular muscle. Circ Res 1964;14:44-60.

8. Wiggers CJ, Wegria R, Finera B. The effects of myocardial ischemia on the fibrillation threshold: the mechanisms of spontaneous ventricular $f$ brillation following coronary artery occlusion. Am J Physiol 1940;131: 309-316.

9. Han J. Ventricular vulnerability during coronary occlusion. Am J Cardio 1969;24:857-864

10. Durrer D, VanLier AAW, Buller J. Epicardial and intramural excitation in chronic myocardial infarction. Am Heart J 1964;68:765-776.

11. Wiggers $\mathrm{CJ}$. The mechan ism and nature of ventricular fibrillation. Am Heart J 1940;20:399-412.

12. Scherlag BJ, El-Sherlf $\boldsymbol{N}_{1}$ Hope R, Lazzara R. Characterization and localization of ventricular arrhythmias resulting from myocardial ischemia and infarction. Circ Res 1974;35:372-383.

13. El-Sherif $N$, Hope RR, Scherlag BJ, Lazzara R. Reentrant arrhythmias in the late myocardial infarction period. 2. Pattern of initiation and termination. Circulation 1977;55:702--719.

14. Lazzara R, El-Sherif N, Scherlag BJ. Early and late effects of coronary artery occlusion on canine Purkinje fibers. Circ Res 1974;35:391-399.

15. Frledman P, Stewart JR, Fenoglio $\mathrm{W} \mathrm{dr}$, Wh AL. Survival of subendocardial Purkinje fibers after extensive myocardial infarction in dogs: in vitro and in vivo correlations. Circ Res 1973;33:597-611.

16. Frledman PL, Stewart JH, WH AL. Spontaneous and induced cardiac ar thythmias in subendocardial Purkinje fibers surviving extensive myocardial infarction in dogs. Circ Riss 1973;33:612-626.

17. Horowitz L.N, Spear JF, Moore EN. Subendocardial origin of ventricular arrhythmias in 24 hour old experimental myocardial infarction. Circulation 1976:53:56-63

18. Kupperemith J, Antman EM, Hofiman BF. In vivo electrophysiologic effects of lidocaine in canine acute myocardlal infarction. Circ Res 1975;36: 84-91.

19. Levites R, Haft JI, VanlCatachalapathy D. Elfect of lignocaine on intramyocardial conduction in nonischemic and ischemic canine myocardium. tramyocardial conduction in nonischem

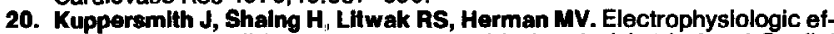
fects of verapamil in carine myocardial ischemia (abstr). Am J Cardiol 1976;37:149.

21. Patterson E, Gibson JK, L.ucchesI BR. Electrophysiologic effects of disopyramide phosphate on reentrant ventricular armythmias in conscious dog after myocardial infarction. Am J Cardiol 1980;46:792-799.

22. Horowliz LN, Josephson ME, Farshidl A, Spielman SR, Michelson EL, Greenspan AM. Recurrent: sustained ventricular tachycardia. 2. Role of the electrophysiologic

23. Lle KI, Wellens HJ, VanCapelle FJ, Durrer D. Lidocaine in the prevention Lle KI, Wellens Hd, VanCapelle FJ, Durrer D. Lidocaine in the prevent

24. Patterson E, Gibeon JK, L.ucchesi BR. Electrophysiologic actions of lidocaine in a canine model of chronic myocardial ischemic damage: arrhythmogenic actions of lidoca.ine. J Cardiovasc Pharmacol 1982;4:925-934.

25. Ruskin JN, DiMarco JP, Garan H. Out-of-hospital cardiac arrest. Electrophysiologic observations and selection of long-term antiarthythmic therapy. N Engl J Med 1980;303:607-613.

26. Josephson ME, Horowltz LN, Greenspan AM, Spielman SR, Kastor JA. Electrophysiologic findings in patients suffering cardiac arrest (abstr). Am $\mathrm{J}$ Cardiol 1979;45:406.

27. Josephson ME, Horowit: LN, Splelman SR, Greenspan AM. Electrophysiologic and hemodynamic studies in patients resuscitated from cardiac arrest. Am J Cardiol 1980;46:948-955

28. Kehoe R, Bauernfiend RA, Wyndham CRC, Meyers S, Talano J, Rosen $K$. Inducible ventricular tzichycardia in patients with out-of-hospital ventricular fibrillation (abstr). Am J Cardiol 1980;45:444.

29. Farshidi A, Mlcheleon EL, Greenspan AM, Spleiman SR, Kastor, JA. Repetitive responses to ventricular extrastimull: incidence, mechanism, and significance. Am Heart J 1980;100:59-68.

30. Schuster EH, Bulkley BH. Ischemia at a distance after acute myocardial infarction. A cause of early post-infarction angina. Circulation 1980;62: $508-515$.

31. Josephson ME, Kaster JA, Horowitz LN. Electrophysiologic management of recurrent ventricular tachycardia in acute and chronic ischemic heart disoase in: Castellanos A ed Cardlac Arrtythmias: Mechanisms and disease. In: Castellanos A ed., Cardlac Arrtythmias: Mechanisms
Manacement. Cerdiovascular Clinics. Phlladetphla: F. A. Davis Co., 1980.

32. May GS, Furberg CD, Eberlein KA, Ceraci BJ. Secondary prevention after myocardial infarction: a review of short-term acute phase trials. Prog Car diovasc Dis 1983;25:335-359. 33. Ruskin J, Mceovern B, Garan H, DMarco JP, Kelty E. Antiannythmic chugs: 309:1302-1306

34. Roy D, Waxman HL, Klentele MG, Buxton AE, Marchlinskl FE, Josepheon ME. Clinical characteristios and long-term foliow-up in 119 survivors of cardiac arrest: relation to inducibility at electrophysiologic testing. Am J Cardiol 1983;52:969-974.

35. Splelman SR, Yacone LA, Greenspan AM, Wobb CR, Horowliz N. Elec- trophysiologic testing in high risk patients with nonsustained ventricular tachycardia and abnormal ventricular function (abstr). Circulation 1983; 68(suppl III):56.

36. Sinch BN, Venkatesh N. Prevention of myocardial reinfarction and of sudden death in survivors of acute myocardial infarction: role of prophylactic beta-adrenoreceptor blockade. Am Heart J 1984:107:189-200.

37. Lucchesi BR, Gibson JK, Anderson J, Patterson E. Sudden coronary death and pharmacologic interventions in electrophysiologic mechanisms underlying sudden cardiac death. Sobel BE, Dingell JV, Mock MB, eds. Moun Kisco, NY: Futura, 1982:207-241.

38. Boura ACA, Green AF. Actions of bretylium: adrenergic neuron blocking and other effects. Br J Pharmacol 1959;14:536-546.

39. Chatterlee K, Mandel WJ, Vyden JK, Parmley WW, Forrester JS. Cardiovascular effects of bretylium tosylate in acute myocardial infarction. JAMA 1973;223:757-760.

40. Anderson JL, Patterson E, Wagner JG, Johnson TA, Lucchesi BR, Pitt B. Clinical pharmacokinetics of intravenous and oral bretylium tosylate in survivors of ventricular survivors of ventricular tachycardia or fibrillation. Clinical application
a new assay for bretylium. J Cardiovasc Pharmacol 1981;3:485-499.

41. Woosley RL, Reeve SB, Rosen DM, Nles AS, Oates JA. Pharmacologic reversal of hypotensive effects complicating antiarrhythmic therapy with bretylium. Clin Pharmacol Ther 1982;32:313-321.

42. Patterson E, Gibson JK, Lucchesi BR. Postmyocardial infarction reentrant ventricular anthythmias in conscious dogs: suppression by bretylium tosylate. J Pharmacol Exp Ther 1981;216:453-458.

43. Andersoon JL, Patterson E, Conlon M, Pasyk S, PHt B, Lucched BR. Kinetics of antifibrillatory effects of bretylium: correlation with myocardial drug concentrations. Am J Cardiol 1980;46:583-592.

44. Fuljmoto $T$, Hamamoto $H$, Peter $T$, McCullen A, Melvin $N$, Mander WJ. Electrophysiologic effects of bretylium on canine ventricular muscle during acute ischemia and reperfusion. Am Heart J 1983;105:966-972.

45. Glbson JK, Stewart JR, LI Y-P, Lucchesi BR. Electrophysiologic effect of bretylium tosylate on the canine heart during coronary artery occlusion and reperfusion. J Cardiovasc Pharmacol 1983;5:517-524.

46. Cardinal R, Sasyniuk BI. Electrophysiologic effects of bretylium tosylate on subendocardial Purkinje fibers from infarcted canine hearts. J Pharmacol Exp Ther 1978:204:159-174.

47. Bacaner M. Bretylium tosylate for suppression of induced ventricular $\mathrm{fi}$ brillation. Am J Cardiol 1966;17:528-534.

48. Bacaner MB. Treatment of ventricular fibrillation and other acute amhythmias with bretylium tosylate. Am J Cardiol 1968;21:530-543.

49. Bacaner M, Schrienemachers D. Bretylium tosylate for suppression of ventricular fibrillation after experimental myocardial infarction. Nature 1968;220:494-496.

50. Kaiffen FJ, Lomas TE, Counsell RE, Lucchesi BR. The antiarrhythmic and antifibrillatory actions of bretylium and its o-iodobenzyl trimethyl ammonium analog, UM-360. J Pharmacol Exp Ther 1975;192:120-128.

51. Sanna G, Arcidlacono R. Chemical ventricular defibrillation of the human heart with bretylium tosylate. Am J Cardiol 1973;32:982-987.

52. Steinberg Mi, Malloy B. Clofilium: a new antifibrillatory agent that selectively increases cellular refractoriness. Life Sci 1979;25:1397-1906.

53. Cervonl P, Ellis CH, Maxwell RA. The antiarrythmic action of bretyllum in normal reserpine-pretreated and chronically denervated dog hearts. Arch int Pharmacodyn Ther 1971;190:91-102.

54. Namm DH, Wang CM, El-Sayad S, Copp FC, Maxwell RA. Effects of bretylium on rat cardiac muscle: the electrophysiological effects and its uptake and binding in normal and immunosympathectomized rat hearts. $J$ Pharmacol Exp Ther 1975;193:194-208.

55. Babbs CF, YIm GKW, Whistler SJ, Tucker WA, Geddes LA. Elevation of ventricular defibrillation threshold in dogs by antiarnythmic drugs. Am Heart J 1979;98:345-350.

58. Tacker WA, Mlebauer MJ, Babbs CF, Holmes HR, Figher DG, Geddes LA. The effect of newer antiarrhythmic ơrugs on defibrillation threshold. Crit Care Med 1980;8:177-180.

57. Haynes RE, Chinn TL, Copass MK, Cobb LA. Comparison of bretylium tosylate and lidocaine in management of out-of-hospital ventricular flbrillation: a randomized clinical trial. Am J Cardiol 1981;48:353-356.

58. Nowak RM, Bodnar TJ, Droven S, Contzkow G, Tomianovich MC. Bretylium tosylate as initial treatment for cardiopulmonary arrest: randomized comparison with placebo. Ann Emerg Med 1981;10:404-407.

59. Terry G, Vellani CW, Higgins MR, Dolg A. Bretylium tosylate in treatment of refractory ventricular arrhythmias complicating myocardial infarction. of refractory ventricular

60. Bermstein JG, Koch-Weser J. The effectiveness of bretylium tosylate against ventricular arrhythmias. Circulation 1972;45:1024-1034.

61. Holder DA, Sniderman AD, Fraser G, Fallen EL. Experience with bretylium tosylate by a hospital cardiac arrest team. Circulation 1977;55:541544. 62. Dhurandhar RW, Pickron J, Coldman AM. Bretylium tosylate in the man-
agement of recurrent ventricular fibrillation complicating acute myocardial infarction. Heart Lung 1980;9:265-270.

63. MacAlpin RN, Zells EG, Kivowltz CF. Prevention of recurrent ventricular tachycardia with oral bretylium tosylate. Ann Intern Med 1970;72:909912 .

64. Slingh B. Amiodarone: historical development and pharmacologic profile. Am Heart $\mathrm{J} 1983 ; 106: 788-797$

65. Nademanee K, Singh B, Cannon DS, Welse J, Feld G, Steveneon WG. Control of sudden recurrent deaths: role of amiodarone. Am Heart $j$ 1983; 106:895-904

66. Greene HL, Werner JA, Gross BW, Sears GK, Trobaugh GB, Cobb LA. Prolongation of cardiac refractory times in man by clofllium phosphate, new antiarrhythmic agent. Am Heart J 1983;106:492-501.

67. Nathan AW, Hellestrand KJ, Bexton RS, Ward DE, Spurrell RAJ, Camm Ad. Electrophysiological effects of sotalol: just another beta blocker? Br Heart J 1982;47:515-520.

68. Stroobandt R, Kesteloot H. Efficacy of intravenous sotalol on ventricutar arrhythmias occurring during maximal exercise stress testing. Arch Int Pharmacodyn Ther 1983;264:290-297. 